\title{
Determinación de Listeria monocytogenes en quesos blancos artesanales expendidos en la plaza de mercado de Cáqueza, Cundinamarca
}

\author{
Deissy Milena Baquero Acuña, Astrid Marcela Bernal González, \\ Silvia Campuzano Msc. \\ Universidad Colegio Mayor de Cundinamarca \\ Correspondencia: scampuzano@unicolmayor.edu.co
}

Recibido: 07-09-2006 / Aceptado: 16-11-2006

\begin{abstract}
Resumen
Las intoxicaciones alimentarías son un problema de salud pública, ya que estas se presentan en cualquier tipo de población aumentando la prevalencia en personas inmunosuprimidas, mujeres embarazadas y personas de edad avanzada. Según los datos obtenidos, el $80 \%$ de las muestras positivas para Listeria spp presentaron Listeria monocytogenes y el $20 \%$ Listeria innocua, indicando una prevalencia de la especie patógena para los humanos, aumentando el riesgo en la población de padecer enfermedades gastrointestinales y/o sistémicas especialmente en ancianos, personas inmunosuprimidas, mujeres embarazadas y niños. De la misma forma, se determinó que el 100\% de los quesos presentaban alguna contaminación microbiana. Se recolectó información acerca de los procesos de elaboración y de almacenamiento de los quesos, igualmente se observó la forma de manipulación de los alimentos en los puntos de venta.

Palabras claves: enfermedades gastrointestinales, intoxicación alimentaria, Listeria monocytogenes, Listeria inoccua, mastitis.

Abstract

Food poisoning is a public health problem, because it can show up in any population being more prevalent in people whose immune system is compromised, pregnant women, and the elderly. According to the obtained data, $80 \%$ of the positive results for Listeria spp showed Listeria monocytogenes and $20 \%$ presented Listeria innocua. This indicates a prevalence of the pathogenic species for humans, thus augmenting the risk for people to suffer from gastrointestinal and/or systemic disease especially in the population mentioned above. In the same way, it was determined that $100 \%$ of the cheese showed some microbial contamination. Information about the cheese elaboration and storing processes was collected and, in the same way, the manner food was handled in stores was observed.
\end{abstract}

Key words: food poisoning, gastrointestinal disseases, Listeria monocytogenes, Listeria innocua, mastitis, 


\section{Introducción}

Las infecciones alimentarías son un tema de preocupación mundial en salud pública, estas infecciones han sido producidas por diferentes microorganismos algunos con gran incidencia: Escherichia coli, Salmonella s.p. Vibrio cólera, Listeria monocytogenes, entre otras presentes en una gran variedad de alimentos de consumo diario (1-14).

Listeria monocytogenes es una bacteria que se caracteriza por ser un cocobacilo Gram positivo intracelular, distribuido ampliamente en la naturaleza en el agua, suelo, vegetación y en desperdicios animales. También se ha observado que animales domésticos y mamíferos salvajes pueden ser el reservorio de este microorganismo (9-12).

La bacteria ha sido aislada de diversos alimentos, especialmente de productos crudos como carnes, leche y todos los derivados lácteos elaborados con leches no pasteurizadas. Listeria puede formar parte de la flora microbiana de la ubre de la vaca y muchas veces se encuentra produciendo mastitis, ya sea clínica o subclínica, lo cual ocasiona la contaminación de la leche $(4,7)$.

Listeria monocytogenes es una bacteria patógena que resiste a diferentes condiciones ambientales, como $\mathrm{pH}$ bajo, altas concentraciones de sal y especialmente tiene la capacidad de sobrevivir a temperaturas de refrigeración $\left(2-4{ }^{\circ} \mathrm{C}\right)$. Todas estas propiedades favorecen la contaminación de los alimentos desde su elaboración, distribución, almacenamiento, comercialización hasta su consumo $(7,11,13)$.

Después de la ingestión de Listeria monocytogenes, comienza un proceso invasivo, el microorganismo penetra las células intestinales hasta llegar al torrente sanguíneo para finalmente causar meningoencefalitis y septicemias. La enfermedad producida por este microorganismo es conocida como listeriosis y la población que se ve más afectada son los ancianos, personas inmunosuprimidas y mujeres embarazadas, causando afecciones en el recién nacido y llegando a producir abortos $(2,13)$.
Los métodos para el análisis de los alimentos en busca del microorganismo son diversos en Colombia, los más utilizados son las pruebas microbiológicas, las cuales son bastante largas y requieren suficiente tiempo para la emisión del resultado. Son pocas las empresas que realizan pruebas especificas y de alta confiabilidad como lo son las pruebas de biología molecular como la Reacción en Cadena de la Polimerasa (PCR) $(6,12)$.

Estudios realizados en Colombia muestran que un producto que se puede encontrar frecuentemente contaminado es el queso artesanal, debido a que muchas veces éste es elaborado con leches crudas que contienen el microorganismo. El queso, gracias a todos sus componentes nutricionales, hace que este sea un perfecto medio de cultivo para el crecimiento de Listeria, inclusive estando en condiciones de refrigeración (1-3).

En Caqueza, Cundinamarca, la mayoría de quesos que se comercializan son de tipo artesanal, la forma de expendio de este producto no es la más adecuada, y junto con la presencia de un clima templado favorecen el crecimiento del microorganismo en el producto; consecuentemente existe la posibilidad de que se afecte el consumidor; por consiguiente, el objetivo del presente estudio fué determinar la presencia de Listeria monocytogenes en quesos artesanales que se comercializan en la plaza de mercado de Caqueza, Cundinamarca; con el fin de sugerir medidas de control que eviten la contaminación del producto.

\section{Materiales y métodos}

Se realizó un estudio de tipo analítico, transversal durante el mes de agosto de 2006, donde se estudió la presencia de Listeria monocytogenes en quesos frescos artesanales comercializados en la plazas de mercado de Caqueza, Cundinamarca.

La población accesible fueron los quesos blancos elaborados artesanalmente que son expendidos en la plaza de mercado de Cáqueza, Cundinamarca, de los cuales, mediante muestreo aleatorio simple, se seleccionaron 30 quesos. 


\section{Presencia de microorganismos en la muestra estudiada.}
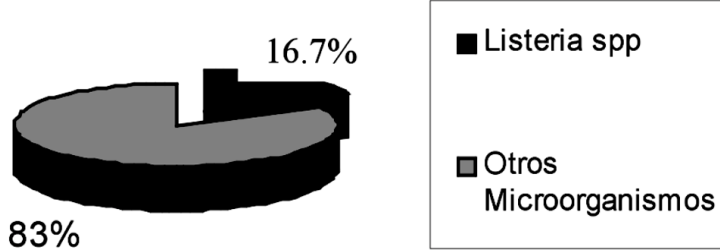

Figura 1. Presencia de microorganismos en las muestras de queso artesanal proveniente de la plaza de mercado de CaquezaCundinamarca.

Para el aislamiento y la detección cualitativa de Listeria spp, se utilizó el método horizontal para el aislamiento de Listeria monocytogenes, establecido por la Secretaria Distrital de Salud: enriquecimiento selectivo primario: Listeria spp. (LEB), aislamiento selectivo: Agar Oxford y Agar Palcam, purificación: Agar Tripticasa Soya Extracto de Levadura (TSAYE), identificación Pruebas bioquímicas y fisiológicas, confirmación con BBL Cristal.

\section{Resultados}

Los resultados de este estudio demuestran la presencia de Listeria spp. en el $16.7 \%$ de los quesos analizados y el hallazgo de diferentes microorganismos como levaduras y otras bacterias en el $100 \%$ de las muestras, Figura 1. En el estudio realizado por la Secretaria Distrital de Salud durante el año 2002 se determinó una frecuencia de L. monocytogenes en quesos del $5.2 \%$. frecuencia relativamente baja comparada con la encontrada en el presente estudio (13.3\%).

Según los datos obtenidos, el $80 \%$ de las muestras positivas para Listeria spp presentaron Listeria monocytogenes y el 20\% Listeria innocua, indicando una prevalencia de la especie patógena para los humanos, aumentando el riesgo en la población de padecer enfermedades gastrointestinales y/o sistémicas especialmente en ancianos, personas inmunosuprimidas, mujeres embarazadas y recién nacidos.

\section{Discusión}

En el presente estudio se determinó la presencia de Listeria spp. en el $16.7 \%$ de la muestra estudiada y de este porcentaje el $80 \%$ correspondía a Listeria monocytogenes. Adicionalmente todos los quesos presentaron algún tipo de contaminación microbiana.

La presencia de microorganismos en los alimentos se debe a malas condiciones higiénico-sanitarias de manejo del producto desde su elaboración hasta su comercialización. En el caso estudiado, en el 100\% de los establecimientos muestreados se observó la utilización de leche cruda para la elaboración del producto, ausencia de sistemas de refrigeración, manejo inadecuado de basuras, presencia de artrópodos y perros en la zona, deficiencias en la forma de conservación del queso, se utilizan hojas de plátano sin que estas reciban ningún tratamiento desinfectante, utilización de canecas contaminadas, etc.

Los resultados obtenidos muestran la urgencia de implementar medidas de control que permitan disminuir la contaminación de los quesos y por consiguiente del riesgo para los consumidores. De esta forma es urgente y prioritario capacitar a los expendedores de quesos en las plazas de Mercado del país para que ellos puedan ofrecer un producto de calidad, que ofrezca seguridad al consumidor. Llama la atención que existan estudios previos donde se informe alta contaminación microbiana de productos lácteos en estos expendios sin que se hayan tomado las medidas pertinentes y/o éstas no hayan sido efectivas.

\section{Referencias}

1. Pardo L, Molina D, Catañeda S. Frecuencia de Listeria monocytogenes en derivados lácteos analizados en el laboratorio de salud publica de la Secretaria Distrital de Salud de Bogotá en el 2001 y 2002.

2. Crespo M, Vélez J, Castañeda C, Hoyos F, López M, Salazar J. Aislamiento de Listeria monocytogenes en un hospital de tercer nivel. Revista Colombia Médica. Universidad del Valle. Vol. $30 \mathrm{~N}^{\circ}$ 2, 1999.

3. Organización Panamericana de la Salud (O.P.S.). Prevención y Diagnóstico de enfermedades. Informe Anual del Director. O.P.S. Washington D.C., 1998: 65-79p.

4. Weis J, Seiger H. Incidence of Listeria monocytogenes in Nature. Appl Microbiology. American Society for Microbiology. U.S.A. July 1975; 30: 29-32. 
5. Gray $\mathrm{M}$ and Killinger A. Listeria monocytogenes and listeric infections. Bacteriol. 1996; 30:276-281.

6. Bille J. Epidemiology of human listeriosis in Europe, with special referente to the Swiss outbreak, in Food Borne Listeriosis. Elsevier, Amsterdam. 1990:71-74.

7. Schlech W, Lavigne P, Bortolussi R. Epidemic listeriosisevidence for transmission by food. The New England Journal of Medicine. 1983;308 (4): 203-206.

8. Dalton C, Agustin R, Sobel J, et al. An outbreak of gastroenteritis and fever due to Listeria monocytogenes in milk. The New England Journal of Medicine.1996; 336: 100-105.

9. Bell C. Listeria, una aproximación práctica al microorganismo y su control en los alimentos. Ed. Acribia S.A. Zaragoza, España. 2002.
10. Gallego M, Torres O, Soto C, Duque D, Benítez C. Determinación de portadores de Listeria $s p$. en un conglomerado lechero de la vereda Puente de Piedra del municipio de Madrid Cundinamarca. Colombia. 2003.Tesis-

11. Sim J, Hood L, Finnie M, Wilson G, Brett H. Series of incidents of Listeria monocytogenes non- invasive febrile gastroenteritis involving ready-to-eat meats. Letters in Applied Microbiology. 2002 (35): 409-413

12. Jay J. Modern Food Microbiology. Editorial An Aspen Publication Inc. Gaithersburg, Maryland. 2000.

13. Vázquez M, Kuhn P, Chakraborty G, Dominguez B, et al. Listeria Pathogenesis and Molecular Virulence Determinants. Clinical Microbiology Reviews. 2001;14 (3): 584-64.

14. Buchanan R. et al. Evaluación de riesgos de Listeria monocytogenes en alimentos listos para el consumo. FAO/ OMS 2004. 